\title{
The Distance Education Evolution: Issues and Case Studies
}

D. Monolescu

C. Schifter

L. Greenwood

Gisela Gil-Egui

Fairfield University, ggil-egui@fairfield.edu

S. F. Shields

See next page for additional authors

Follow this and additional works at: https://digitalcommons.fairfield.edu/communications-books Copyright 2003 Idea Group Publishing

Content archived her with permission from the copyright holder.

\section{Recommended Citation}

Monolescu, D.; Schifter, C.; Greenwood, L.; Gil-Egui, Gisela; Shields, S. F.; and Stewart, C. M., "The Distance Education Evolution: Issues and Case Studies" (2003). Communication Faculty Book Gallery. 10.

https://digitalcommons.fairfield.edu/communications-books/10

This item has been accepted for inclusion in DigitalCommons@Fairfield by an authorized administrator of DigitalCommons@Fairfield. It is brought to you by DigitalCommons@Fairfield with permission from the rightsholder(s) and is protected by copyright and/or related rights. You are free to use this item in any way that is permitted by the copyright and related rights legislation that applies to your use. For other uses, you need to obtain permission from the rights-holder(s) directly, unless additional rights are indicated by a Creative Commons license in the record and/or on the work itself. For more information, please contact digitalcommons@fairfield.edu. 
Author(s)

D. Monolescu, C. Schifter, L. Greenwood, Gisela Gil-Egui, S. F. Shields, and C. M. Stewart 


\title{
The Distance Education Evolution: Issues and Case Studies
}

\author{
Dominique Monolescu \\ Temple University, USA \\ Catherine Schifter \\ Temple University, USA \\ Linda Greenwood \\ Temple University, USA
}


Acquisition Editor:

Senior Managing Editor:

Managing Editor:

Development Editor:

Copy Editor:

Typesetter:

Cover Design:

Printed at:

\author{
Mehdi Khosrow-Pour \\ Jan Travers \\ Amanda Appicello \\ Michele Rossi \\ Jane Conley \\ Jennifer Wetzel \\ Michelle Waters \\ Integrated Book Technology
}

Published in the United States of America by

Information Science Publishing (an imprint of Idea Group Inc.)

701 E. Chocolate Avenue, Suite 200

Hershey PA 17033

Tel: 717-533-8845

Fax: 717-533-8661

E-mail:cust@idea-group.com

Web site: http://www.idea-group.com

and in the United Kingdom by

Information Science Publishing (an imprint of Idea Group Inc.)

3 Henrietta Street

Covent Garden

London WC2E 8LU

Tel: 442072400856

Fax: 442073793313

Web site: http://www.eurospan.co.uk

Copyright (C) 2004 by Idea Group Inc. All rights reserved. No part of this book may be reproduced in any form or by any means, electronic or mechanical, including photocopying, without written permission from the publisher.

Library of Congress Cataloging-in-Publication Data

The distance education evolution : issues and case studies / [edited by]

Dominique Monolescu, Catherine Schifter, and Linda Greenwood.

p. $\mathrm{cm}$.

Includes bibliographical references.

ISBN 1-59140-120-8 (hardcover) -- ISBN 1-59140-121-6 (ebook)

1. Distance education--Computer-assisted instruction. 2. Education, Higher--Computer-assisted instruction. 3. Educational technology. I. Monolescu, Dominique. II. Schifter, Catherine. III. Greenwood, Linda, 1951 -

LC5803.C65D545 2004

$371.3^{\prime} 58--\mathrm{dc} 21$

2003008767

Paperback ISBN 1-59140-224-7

British Cataloguing in Publication Data

A Cataloguing in Publication record for this book is available from the British Library.

All work contributed to this book is new, previously-unpublished material. The views expressed in this book are those of the authors, but not necessarily of the publisher. 


\title{
Chapter V
}

\section{Certain about \\ Uncertainty: Strategies and Practices for Virtual Teamwork in Online Classrooms}

\author{
Stella F. Shields \\ Indiana University, USA \\ Gisela Gil-Egui \\ Temple University, USA \\ Concetta M. Stewart \\ Temple University, USA
}

\section{Abstract}

Many students face the prospect of working in teams with apprehension. This feeling is further magnified when most or all of the sensory cues are removed in the virtual environment. We argue that by adopting specific structural and situational strategies, instructors can substantially reduce 
the levels of uncertainty that usually surround the idea of virtual teamwork in students' minds. Such strategies are drawn from an exploration of the notion of trust as a key element for the successful performance of teams, as well as on a discussion of the concepts of swift trust, community of practice, and control as guiding principles for the establishment of practices that help build mutual reliance among virtual team members in an online classroom. We conclude with some suggestions that can be implemented at the micro level of the course and the macro level of the institution hosting distance and online learning experiences.

\section{Introduction}

"We believe we are experiencing the most dramatic change in the nature of the small group since humans acquired the capacity to talk to one another - the explosion of virtual teams" (Lipnack \& Stamps, 1997, Chapter 2, I 5).

Small human groups have existed for thousands upon thousands of years. These groups were key to the existence of humankind beginning with the Nomadic Age. Their acquisition of food depended on group work. This reality of pre-civilized life becomes especially evident when one considers the mastodon. Mastodons were rather formidable creatures, yet we know that in distant millennia, our predecessors stalked, hunted, and killed them. Among the sites containing evidence of this practice is the Taima-Taima site in coastal Venezuela. Fragments of tools and bones uncovered here revealed that groups were formed to hunt these wooly behemoths, and that they were butchered down to the bone. Facing an animal weighing five tons that towered over them, hunters must have experienced the twin rushes of hope and fear. Yet the reward - food - was greater than the fear of death or the fear of being maimed by a potential repast. The passage from childhood to becoming a hunter must have had moments of terror, but also feelings of kinship and trust for fellow hunters.

Today, the students' passage from adolescence to adulthood is far more prolonged; moreover, the complexity of their lives has often precluded the need to work in a group. Or, if they have been members of a group, their experience might have been negative. Many students, therefore, face the prospect of 
working in groups or teams with great trepidation when they enter our classes. This apprehension exists in the traditional classroom, but it is further magnified when most or all of the sensory cues are removed in the virtual environment. Albert Mehrabian's (1971) formula for the communication of feelings explains that $93 \%$ of the impact of a message in face-to-face interaction is made by nonverbal cues. Kezbom (2000) noted:

Non-verbal communication can account for as much as $60 \%$ of the message an individual conveys. This can entail the furtive glance, a reddening neck, or twitching face ... clues that often convey a plethora of important emotions. Team members who are in separate locations are deprived of these clues that indicate their colleagues' opinions, attitudes, and emotions. Even in the best videoconferencing, facial expressions can be difficult to pick up if the transmission is poor, is someone is off camera, or when the mute button is pressed (p.33).

If so many students have such an innate dislike of working in groups or teams, then why impose such a requirement? And if we impose it, how can we lead them to understand the importance of cooperative, knowledge-constructing, behaviors as well as did those young people who lived well over ten thousand years ago? Although today the risks and rewards of cooperative behavior are different (e.g., failure to master technologies that enable team members to work together does not increase risk of death, but it supposes lost opportunities for efficient work), there are still gains and losses. So is there anything that we can learn from our past to help our students today?

Most importantly, we need to recognize that from our students' perspective, their fears are as real as those of youth millennia ago who feared loss of life or limb. And although our students no longer face hunger, injury, or death if they fail to perform, they find the prospect of working in a team threatening nonetheless. To them, their only reward is a grade, which many feel is actually threatened by working in groups or teams. Fear, uncertainty, lack of experience in learning and working cooperatively are all accentuated by a strong belief in success as an attribute of the individual. Can our students overcome these barriers to virtual teaming?

We argue that by adopting specific structural and situational strategies, instructors and facilitators of online courses can substantially reduce the levels of uncertainty that usually surround the idea of virtual teamwork in students' 
minds. Through measures aimed at building trust and a sense of community, students can not only benefit from the immediate social and practical gains of collaborating with others in performing tasks, but also from valuable processes of participatory learning and collective elicitation of knowledge.

Still, adopting such strategies requires much investment of time, resources, and creativity, and many faculty might question the extent to which establishing virtual teams in academic environments is worth the effort. Once again, one could ask why make group or team work a requirement? The quote by Lipnack and Stamps (1997) that opens this chapter suggests that we are experiencing one of the greatest changes in the "nature of small groups" to happen in thousands of years. Virtual teams will continue to increase, almost exponentially, as they become major components of organizational structures in our Network Age. They might become the dominant organizational form as we move from this age to the next.

In the following section, we will provide further justification for the incorporation of teamwork as a major component of online learning. Next, we will provide some conceptual clarifications regarding the notions of group, teams, and contributors. We will then explore the notion of trust as a key element for the successful performance of teams. And, finally, we will discuss the concepts of swift trust, community of practice, and control as guiding principles for the establishment of short-term and long-term practices that build trust among virtual team members in an online classroom. We conclude our chapter with some practical suggestions that can be implemented at the micro level of the course and the macro level of the institution hosting distance and online learning experiences.

\section{The Network Age}

The 2001 United Nations Development Programme Report describes the Networked age as a creation of the intertwining of "technological transformations and globalization" (UNDP, 2001, p.15). One characteristic of this age is the tremendous growth in distance learning classes and programs, as well as the development of completely virtual educational institutions. Even traditional, small, post-secondary educational institutions - whose strength lies in the relationships between faculty and students, and between students and other 
students - are beginning to integrate Information and Communication Technologies (ICTs) into their "bricks and mortar" classrooms.

Meanwhile, online courses and educational institutions that develop and offer these courses are ever increasing. A survey by the National Center for Education Statistics (2000) found a significant rise in the number of distance learning programs in recent years. Today, according to The International Distance Learning Course Finder (International WHERE+HOW, 2002), there are at least 55, 000 organizations in over 130 countries developing and offering distance courses, many of them based on new ICTs. Furthermore, there are several annual international conferences for online and distance learning practitioners, with at least one of them attracting close to 1,000 participants from more than 50 countries (see, for example, http://www.online-educa.com). And, finally, a growing number of journals addressing education in a virtual, networked, environment have emerged (e.g., Virtual University Journal).

Virtual teams are familiar organizational structures outside academia, where they are already working together to develop and share knowledge, while simultaneously building knowledge structures. These structures reside within the individual group or team members, within the groups or teams, and ultimately within a network of organizations. Although there are still populations around the globe - including many in the U.S. - who are excluded from participation in this Network Age, we now have the possibility and responsibility of seeing that our students fully participate. Our students live in an age where virtual teams are an increasingly important reality of everyday life. This is where our students and our educational institutions need to be situated.

As educators, our mission is to prepare our students for the society in which we live and to which they will be expected to contribute. However, there is a dearth of research on virtual teams and groups in academic institutions. Although they are common in commercial, administrative, and some non-governmental organizations (NGOs), we do not know if they are being generally embraced in higher education. Anecdotally, we are hearing of their adoption in business schools, where most of the existing academic research on the subject seems to be located. We need, however, to conduct more broad-based research to better understand the process and outcomes of student virtual teams, so that our students are able to function in the institutions for which we are putatively preparing them.

We believe that the virtual teaming process itself determines individual and team outcomes, for it is this process that determines the ability of individual members 
to participate as well as the development path of the team itself. The degree of success or failure in setting goals, completing tasks, and ultimately finishing the projects we give groups and teams reflects on the processes that are employed. Consequently, learning the processes of virtual collaboration is crucial to both individual and team achievement.

In industry, the importance of group processes is borne out by the research of Lurey and Raisinghani (2001), who collected and analyzed data from 67 individuals who were members of 12 virtual teams working in eight companies. These individuals belonged to the high technology, agriculture, and professional services industries. Results of this study suggest "teams' processes and team members' relations presented the strongest relationships to team performance and team member satisfaction" (Lurey \& Raisinghani, 2001, p.524). Our experience leads us to believe these same findings could also be borne out in research on virtual student teams.

\section{Clarifying Concepts}

\section{Groups or Teams?}

Let us again imagine we can observe our young mastodon hunters across the millennia. We might think of them as banding together with a common purpose and a common knowledge structure based on common experiences and teachings that adults transmitted to them from birth. This culture of collaboration greatly simplifies the process of teaming and, over time, increasingly contributes to positive outcomes for the teams.

Today, we attempt to define common purpose and goals in our syllabi. We work to build some sort of community in our class - be it traditional or virtual - so that our students feel a sort of common identity. But, unlike the case of the mastodon hunters, there is no shared understanding of reality that older members of the community can transmit to the younger ones. Instructors and students are lacking in many common knowledge structures and experiences of the virtual environment. So when we refer to our students working in groups or teams, we do so without reflecting upon the validity of the terms.

In 2001, we asked 93 students in three traditional classes to describe differences between teams and groups in classroom discussions. ${ }^{1}$ Their an- 
swers could be categorized according to purposes, relationships, and processes. First, with regard to purposes they stated: "Teams have a common goal, to win" versus "Groups don't really have goals." Second, they described group relationships as follows: "Members of the team stay together," and "Team members hang together outside of practice and games," versus "People in groups join and drop out," and "Groups are large." Finally, they described the process: "In teams, each member does his best," versus "In groups, each person might do something."

Our students implicitly defined teams as important and as having a common goal - to win. Individual responsibility was also quite important because each individual contributed to or took away from the goal of the team, and were held accountable for their contribution to the team's performance. They could be "benched" or "penalized" based on reports of their poor performance made available to the instructor by other team's members. This decision was sometimes accompanied by a sense of letting down the team and their friends. Team members were supposed to be friends. They were supposed to like being together.

These students also defined group membership as a bit amorphous, and group activities were also unclear. In their class discussions, it seemed that while some individuals in groups might be friends, group members did not socialize as a group. (It should be noted, however, that the students participating in this particular discussion were a rather homogenous population with gender about evenly divided, so cultural differences did not play a role in their definitions.)

\section{Defining Real and Virtual Teams}

We frequently hear "team" applied to any work group, and many times it is used interchangeably with the term "group." Katzenbach and Smith (2001) provide a more precise definition of a team as: "A small number of people with complementary skills who are committed to a common purpose, set of performance goals, and approach for which they hold themselves mutually accountable" [emphasis added] (\$ 5). Conversely, they define working groups as hierarchical entities with one strong leader. And, in this case, accountability is individual, though the group may work together on issues.

According to some researchers, purpose is a distinctive feature of teams. Lipnack (as cited by Cantu, 1997) notes that: 
When the exercise of writing a purpose statement becomes the basis [for teamwork], it is a powerful source of energy. The importance of a virtual team going through a process to make its purpose tangible cannot be overstated... Ultimately, this means writing down the purpose statement of intent that answers the question "Why are we doing this?" Make explicit the team's mission - its top-most goal and motivation to action. Although it may be difficult, it is essential that the virtual team gets the purpose right and makes it clear to everyone (p.35).

Team leadership shifts. Team members work together to solve a problem and then they implement the solution. Katzenbach and Smith $(2001,97)$ further argue that if performance goals can be achieved through "the sum of individual assignments and achievements, then you should not use a team approach."

According to Gould (1999), virtual team characteristics are:

- "Members are mutually accountable for team results.

- Members are dispersed geographically (nationally or internationally).

- Members work apart more time than in the same location.

- The team solves problems and makes decisions jointly.

- The team usually has fewer than 20 members.”(Gould, 1999, \14, citing Henry \& Hartzler, 1997)

Lipnack and Stamps (1997, Ch. 1, 9 4) define the virtual team as working “... across space, time, and organizational boundaries with links strengthened by webs of communication technologies." Recognizing the unique challenges of virtual teamwork, these authors have identified some principles that allow virtual teams to form quickly and solve complex problems:

- People: Virtual teams are composed of independent members with significantautonomy and self-reliance. Leadershipis informal, and shared. Most members are leaders at some point in the process.

- Purpose: The virtual team creates cooperative goals, undertakes independent tasks and reaches for concrete results.

- Links: The explosion in communication technologies allows for the creation of virtual teams. Multiple, constantly enhanced modes of commu- 
nication are possible, providing access to vast amounts of information and interaction. Virtual teams operate on Internet time" (Lipnack \& Stamps, 1997, Ch. 1, I 5).

\section{Individual Member Contributions}

How do individuals contribute to teams? Once again, we turn to research conducted in industry. And according to Bandow (2001):

The difference between success and failure may no longer lie in technology or methods, but in how individuals contribute to teams. Team members have discovered that poor working relationships and lack of trust within the group may interfere with how effectively individuals contribute to teams, reduce overall team performance, increase cycle time, create higher costs and potentially impact product quality (p.41).

Students who work in virtual teams face many of the same problems faced by members of virtual teams in industry. However, the basis for selection of team members is very different in the academic environment. In building crossfunctional teams, members of teams in industry are selected for their respective skills or expertise. It is expected that each member's contribution relates to these skills and expertise. Allocation of responsibility in student teams is not usually based on special skills or expertise. Team membership is more often than not a matter of happenstance, and all of the members are all expected to equally learn the content of the course.

\section{Bonding Beyond the Task}

Mutual knowledge seems to be a common assumption of both faculty and students in the creation and process of team activities. However, Cramton (2001, p. 2) identified five kinds of problems constituting failures of mutual knowledge. They are "failure to communicate and retain contextual information, unevenly distributed information, difficulty communicating and understanding the salience of information, differences in speed of access to information, and difficulty interpreting the meaning of silence" (Cramton, 2001, $\mid 2$ ). 
Any of the failures mentioned above could lead to distrust and the breakdown of social bonds among the team members. At issue is the fact that mutual knowledge is at the core of successful virtual teaming, but its actual development relies on that very same process.

Many researchers emphasize the need for trust in virtual teams. It is seen to increase team interaction and collaboration, healthy discussions involving conflict, and the equitable distribution of power and respect within the team. Lipnack and Stamps $(1997$, Ch. 9, $\mid 4)$ state that "[b]uilding trust is a key factor in building an effective virtual team.". Bandow (2001) argues that working relationships are built on trust. Information flows freely, there is no concealment, agreements are honored, and there is acceptance and collaboration. Work becomes the focus rather than the "politics, assumptions and innuendo found in human behavior" (Bandow, 2001, p.44).

Trust is closely related to the notion of social capital. "Task success (is) the value of the results" and "Social success (is) the value of the relationships" (Lipnack \& Stamps, 1997, Ch. 9, \6). When both factors are combined, they form "Social Capital, the community of wealth that co-evolves when people work together" (Lipnack \& Stamps, 1997, Ch. 9, ๆ 8). We have long known the importance of the socialization process of members into organizations. However, we still do not know enough about it in virtual teams. This process of socialization is undoubtedly related to trust and warrants closer examination.

\section{Trust: A Multidimensional Concept}

Departing from positions that attributed a deterministic role to technology as the enabler of tele-collaboration, researchers are now paying greater attention to complex socio-psychological factors involved in the performance of virtual teams. A review of relevant literature on the new cooperative paradigm that is gaining strength in organizations worldwide reveals that trust is increasingly recognized as a key factor for the success of teamwork, especially when team members are physically distant from one another.

However, this same scholarly work also reveals absence of a commonly accepted definition of trust. Mayer, Davis, and Schoorman (1995), for example, consider trust to be a function of both attitudinal and situational factors. On the one hand, an individual's propensity to trust is a personality trait 
that "is assumed to be stable during the relationship as well as from one situation to another, and is influenced by a trustor's cultural, social, developmental experiences, and personality type" (Jarvenpaa, Knoll \& Leidner, 1998, p.31, citing Mayer et al., 1995). On the other hand, situation-related trust will be determined by perceived attributes of the trustee with regard to his or her ability (that is, competence to deal with an issue), benevolence (disposition to care for others beyond egoistic motives), and integrity (discipline, professionalism, work/study ethics).

As McKnight and Chervany (2001) observe, "[t]rust conceptualizations have ranged from a personality construct, to a rational choice, to an interpersonal relationship, to a social structure construct" (p. 30). According to these authors, trust is a multidimensional notion. Therefore, after exploring definitions from different disciplines and approaches, they propose a categorization of the term that comprehends the following factors:

- Disposition (tendency to rely on others in general, regardless of the person or situation);

- Intention (willingness to depend on a specific person, regardless of the situation);

- Belief/Expectation (conviction that the trustee is competent, benevolent, predictable, and/or has integrity, in light of a specific situations);

- Behavior (voluntary act of reliance on other person, such as that taking place when two parties share information or cooperate); and

- Context (structural and/or situational conditions are considered both normal and adequate to reduce risks involved in depending on others).

By arguing that trust is a complex concept and proposing the trust typology described above, McKnight and Chervany (2001) seek to provide constructs that are both comprehensive enough to be meaningful for different disciplines and specific enough to allow operationalizations and empirical measures. As we shall explain later, all the dimensions of trust considered above are relevant for academic environments, because performance of virtual teams in online classrooms involves individual, interpersonal, group, and institutional task.

Unfortunately, most of the literature available on trust and virtual teams focuses on non-academic contexts, with few exceptions (e.g., Bitter-Rijpkema, Martens, \& Jochems, 2002; Crisp \& Jarvenpaa, 2000; Jarvenpaa \& Leidner, 1998). Perhaps a reason for this omission is that, although cost and efficiency 
imperatives are prompting the use of virtual teamwork in many organizations worldwide, academia is still largely regarded as an individual-centered and highly hierarchical setting where task-related communication flows vertically, not horizontally. That is, the predominant paradigm in higher education is that communication and information flow from the teacher to the student and back again. Peer-to-peer communication is not considered relevant, or at least not vital.

It is important, thus, to keep in mind some distinctions between academic and other organizational environments when looking at what existing research has to say with regard to the conditions under which trust among virtual team members evolves. Within corporate organizations, assumptions of common denominators regarding practices, authority, expertise, and/or consequentiality facilitates trust building even for geographically dispersed teams put together without mediating any previous acquaintance. In time, the initial mutual reliance generated by those denominators evolves into adjusted expectations, based on observed attributions among team members.

But in the increasingly heterogeneous context of online higher education, where those denominators cannot be taken for granted and where time constraints limit opportunities for members of virtual teams to know each other, trust does not seem to have a solid basis upon which to be built. Students come to the virtual classroom with uneven working styles, levels of self-discipline, technical skills, goals, knowledge of the subject, and, because of their relative independence from instructor's supervision, understanding of power and authority.

\section{Dynamics of Trust}

Does this mean that it is not possible to foster trust within online students' teams? Relevant studies on the issue are at best inconclusive, as scholars disagree on the factors conditioning the establishment of trust-based relationships. However, from the variety of existing explanations about the way trust evolves in different contexts, two main views can be identified: a developmental one, which sees trust growing incrementally as a result of long-term interactions; and a deterministic one, which sees trust as a condition preceding interaction, more likely to remain stable or decrease rather than increase over time (Crisp \& Jarvenpaa, 2000; cfr. Tidwell \& Walther, 2000).

The developmental view rests on the assumption that trust in teams only emerges gradually after members have been able to interact with each other and 
get acquainted (Lewicki \& Bunker, 1995, as cited in Crisp \& Jarvenpaa, 2000). Handy (1995) argues that trust requires touch (face-to-face interaction) to occur, as technology in and of itself cannot compensate for non-verbal clues that are important in human communication. Kimble, Li and Barlow (2000) support this position by contending that performance of effective global virtual teams is informed as much by exchanges in physical space, as it is by communication in the electronic space:

If a strong relationship is developed in the physical environment, members of the community are more likely to "go the extra halfmile" for each other. The feelings of identity and trust developed in this way provide a sound basis for subsequent electronic collaboration (p. 13).

Case studies conducted by Jarvenpaa and Leidner (1998) on virtual teams of college students whose members never met before and lived in different countries suggest that those teams that manage to balance task-oriented communication and social-oriented communication are likely to perform better than teams with little or no social-oriented communication. As long as the social exchange complements rather than replacing the focus on the task it "can make computer-mediated groups 'thicker"' (Jarvenpaa \& Leidner, 1998, p. 29).

In contrast, the deterministic view rests on the assumption that trust (or lack thereof) is brought into teams by members' personal traits and by the circumstances under which they get to work together. The model challenges the developmental view of trust, insisting that initial trust can be quite high even when there is no past interaction history or first hand knowledge of others' characteristics. Initial trust flows from characteristics of the trustor (e.g., an individual's disposition to trust and trusting stance in general) and shared institutional factors (e.g., common professional associations, structural assurances) (McKnight et al., 1998, cited by Crisp \& Jarvenpaa, 2000).

Meyerson, Weick, and Kramer (1996) argue that temporary virtual teams created around specific tasks and with a short life span can manage to perform well despite their limited time for social bonding. Given the impossibility of generating trust over extended processes of mutual acquaintance, individual members will seek to reduce initial uncertainty about their teammates by importing category-driven information available to them, thus forming "stereotypical impressions of others" (Meyerson et al., 1996, as cited by Jarvenpaa \& Leidner, 1998). 
This kind of team will develop "swift trust" that evolves throughout two brief phases. Initially, trust is fed by perceived trustworthiness of the initiator or assembler of the team (who has previously had opportunity to know each member of the temporary group), and by a quick assessment of the risks and potential outcomes (Harrison, Dibben \& Mason, 1997). Once the team members begin working together, trust is sustained by fast-paced, proactive, task-focused interaction in which each team member has a clearly defined role, based on his or her individual field of expertise.

Action strengthens trust in a self-fulfilling fashion: action will maintain members' confidence that the team is able to manage the uncertainty, risk, and points of vulnerability, yet the conveyance of action has as a requisite the communication of individual activities. In summary, whereas traditional conceptualizations of trust are based strongly on interpersonal relationships, swift trust de-emphasizes the interpersonal dimensions and is based initially on broad categorical social structures and later on action. Since members initially import trust, trust might attain its zenith at the project's inception (Meyerson at al., 1996, as cited by Jarvenpaa \& Leidner, 1998, p. $6)$.

The studies listed above represent only a sample of a growing scholarly production that is still struggling to both determine the conditions in which trust occurs and suggest practices to make it happen within formal and informal organizations. However, when considering teams whose members are separated by space (geographic location), place (organizational/institutional location), and situation (role, skills, knowledge, culture), most of this scholarly production finds itself siding with one of two extremes positions: trust among virtual team members is, by default, either ruled out or taken for granted.

\section{Extrapolating "Real World" Experiences to the Classroom}

We believe that the truth of the matter lies somewhere between these extremes. As we stated previously, conditions surrounding virtual teams in distance education settings are very different from those of virtual teams in other 
organizational contexts - a fact that might challenge extrapolation of the notion of swift trust to online classrooms. For example, in virtual classrooms instructors become the initiators of teams, even when they will not be part of them and may not be previously acquainted with their members. Moreover, role assignment within the team may not be determined by expertise, but rather by random selection.

Still, the study by Jarvenpaa and Leidner (1998) provides empirical evidence indicating that, in spite of higher levels of uncertainty about leadership, procedures, role assignment, etc., than those experienced by their counterparts in the "real world," some virtual teams in online classrooms manage to develop swift trust. They do so by engaging in a series of strategies that improve the efficiency and effectiveness of communication among members, consequently affecting overall team performance in a positive way.

But is swift trust enough in the context of online learning? We cannot forget that creation of virtual teams in an online classroom has to serve the overarching goal of effectively conveying curricular contents, beyond providing students with practical training on real workplace situations and use of information and communication technologies. Swift trust among members of virtual teams in online classrooms certainly contributes to the efficient accomplishment of short-term tasks, which is a valuable skill for students to acquire. However, according to Bitter-Rijpkema, Martens, and Jochems (2002) substantial collaborative learning and mutual knowledge elicitation seems to demand broader and longer-term interaction:

Construction of shared understanding and solutions requires more than simple exchange of explicit information. Elicitation of unarticulated ideas of participants lies at the basis of negotiated agreement upon common goals and collective solutions...Researchers emphasize the fact that knowledge elicitation doesn't arise spontaneously... Ideas for stimulation range from elicitation via external knowledge presentations, structured dialogues, argumentation elicitation and the use of artifacts to community formation... Empirical studies (Kraut et al., 1988) indicate that social interaction is so critical to successful knowledge creation that neglecting this aspect will limit collaborative knowledge construction (p. 2).

Facilitators of distance learning environments should, therefore, introduce virtual teamwork to their online classrooms with two timelines in mind: one 
related to the efficient operation of teams under specific deadlines; another related to the development of long-run interactions conducive to participatory and collaborative knowledge creation, as well as coverage of the course content. While the idea of swift trust provides an adequate approach for the adoption of strategies concerning the former, some principles associated with the notion of "structured trust" and community of practice may also prove useful for the latter.

Bandow (2001) argues that "structured trust" facilitates team performance as it provides:

[a] framework around which teams and team members can function when they have little knowledge of others in the group. Standardized processes, contracts and other verbal and written agreements can all serve as forms of structured trust, and managers can facilitate teams to help establish trust structures. When individuals come together to work as a team, they bring many differentopinions with them...Typically, verbal agreements are made within the team, but the problem with verbal agreements is that not everyone hears the same information, even if everyone receives it at the same time. Different assumptions are made based on individual perspectives... Left untouched, these misconceptions can grow into issues of monumental proportions that may never be overcome ( $p$. 42).

\section{Communities of Practice and Virtual Teams in Distance Learning}

In the preceding sections, we have discussed the importance of relationships and bonding for the successful implementation of virtual teams. As we have also mentioned, such bonding is more likely to occur the longer a group remains stable. However, it is a given that students are together for a short period of time represented by a semester, quarter, or trimester. Consequently, understanding the evolution of team formation and communities of practice in this particular setting is key to a successful online learning experience.

Lave and Wenger (1991) first coined the term "Community of Practice" (CoP) to describe a set of social arrangements maintained over time around an 
activity, defined by a specialized language, specific knowledge, unique procedures, and common resources, as well as by virtue of its relationship to other communities. Crucial to this idea is the notion of "Legitimate Peripheral Participation"(LPP), that is, the process by which the community is sustained over time through gradual incorporation of newcomers to the core membership. "Newcomers participate in the periphery, observing old-timers and taking part in legitimate practices. Increasingly, the newcomers are given more responsibility within the community and begin to engage in practices more central to the community" (Squire \& Johnson, 2000, p. 24).

The notion of community of practice has appealed a number of education scholars in recent years, as it can be easily linked to other theories in the field, such as anchored instruction, cognitive apprenticeship, and social learning. ${ }^{2}$ However, few studies have attempted empirical explorations of the establishment and maintenance of CoPs in distributed learning environments such as those typical of distance education (e.g., Barab, Squire, \& Dueber, 2000; Squire \& Johnson, 2000). Even scarcer are studies dealing with the role of information and communication technologies in promoting or hindering CoPs within virtual classrooms.

Still, the incipient literature on the subject seems to indicate that creating adequate structural conditions and processes for a community of practice within an online course should facilitate generation of trust necessary for virtual teams to operate. Findings from the case studies conducted by Jarvenpaa and Leidner (1998), and Kimble et al. (2000) corroborate that academic virtual teams that create procedures for communication and problem-solving (i.e., practices that build participants' identity as members of something larger than an aggregation of individuals) are able to overcome technical and cultural barriers inherent to virtual teamwork.

By the same token, researchers argue that time constraints of formal learning settings make it particularly difficult for teams to engage in the extended procedural and social exchanges that create a community of practice. This, in turn, has a negative impact on the process of building trust and discipline within teams. However, even if teams manage to create a community of practice, they rarely relate to other CoPs (Squire \& Johnson, 2000). Moreover, community maintenance through legitimate peripheral participation does not stand much of a chance because a team's existence rarely transcends the term of the course in which it was created.

Engaging students in communities of practice demands giving them extended periods of time to participate in a community ... 
[S]chool calendars and schedules imposed boundaries on students' participation, and seriously challenged educators' ability to engage learners in communities of practice within school settings...[A] student's participation in a community ended with the termination of the program. If students hoped to continuing participating within a community of practice, they would have to do so largely on their own. Thus providing students with opportunities to participate in communities of practice may require systemic change efforts to make lengthy relationships possible (Squire \& Johnson, 2000, p. 42).

\section{Balancing Trust and Control in the Virtual Classroom}

Both developmental and deterministic views conceive trust as the result of reducing uncertainty with respect to other team members and the conditions under which teamwork takes place. Such uncertainty reduction is possible, according to the developmental model, through extended social interaction or, according to the deterministic model, by filling in voids of actual information with pre-formed ideas, stereotypes, attitudes, and assessments of risks and benefits.

Whereas some studies indicate that trust can not only be learned (and, therefore, taught) in scenarios of relatively short-term interaction(Birk, 2001), but also created in conditions that makes it self-reproductive (Falcone, Singh \& Tan, 2001; Shaw, 1997); understanding trust building in terms of uncertainty reduction opens interesting possibilities for the design of strategies aimed at facilitating teamwork and collaborative learning.

Regarding facilitation of teamwork, a number of authors have underlined the advantages of clearly predefined rules of communication in generating and maintaining trust among team members. These rules range from the use of multiple technological platforms to requiring exchange of individual information among team members (e.g., biographical data, background, interests, photos, and goals) to establishing patterns of frequency and style of interaction. Such procedures for the internal operation of teams can contribute to the emergence of swift trust, as team members exchange some preliminary information about 
their motivations and capacities (for role assignment) and decrease their levels of uncertainty about issues of appropriateness and the organizational culture of the virtual classroom.

With respect to long-term strategies for ensuring collaborative learning, it is important to assess processes as well as results. Instructors or facilitators should not only keep track of communication among team members for timely intervention when conflicts are not adequately addressed, but also let students know that their work is being monitored throughout all phases. The presence of structured mechanisms of control helps reduce levels of uncertainty because it minimizes defection or opportunistic behavior while rewarding collaboration.

Responsibility and accountability are major problems with individual team members. Some do not see themselves as stakeholders, nor are they seriously troubled by the prospect of their behavior potentially lowering the team grade. These problems exist in face-to-face teams, but they can become more difficult to deal with in virtual teams. However, technology does allow the teacher to monitor all individuals and team contributions closely, as well as the evolving relationships of team members.

Control mechanisms have been associated with the notion of distrust, a condition that many times coexists with trust, even as the two terms are conceptual opposites. McKnight and Chervany (2001) explain that while we may trust a particular person in some situations, we may distrust him or her in other circumstances. Because organizations cannot anticipate members' responses in all situations, a balance between dependence and control is necessary (Shawn, 1997). When it comes to virtual teams, "looking at only the positive (trust) side of things can result in such detrimental thought patterns as 'group-think,' [whereas] looking at only the negative (distrust) side can paralyze action" (McKnight \& Chervany, 2001, pp. 46-47).

Lewicki, McAllister, and Bies (1998, p. 439) highlight the complementary nature of the concepts of trustand distrust by defining them respectively in terms of positive or negative expectations regarding some individual's behavior. Thus, they argue that both concepts reflect "movement toward certainty," even if coming from different directions. 


\section{Conclusions}

Preliminary empirical research is just beginning to assess the potential explanatory power and limitations of extrapolating the notions of trust and community of practice from organizational settings to distance education experiences. However, we believe that it is not too early to suggest some strategies to help overcome the problems described above. And although it has been indicated that a re-conceptualization of the way the academic sector approaches virtual teams is necessary, some measures within the current timeframe and structure of traditional distance education programs are possible.

The literature reviewed for this chapter and our own experiences as facilitators and participants in virtual teams, suggest that processes involving trust building (swift and structured), balancing trust and control, and developing communities of practice have as a common denominator a desire to reduce uncertainty. In this sense, we have several suggestions for educational practitioners who are considering the adoption of virtual teams for their classes:

- Reliance on multiple communication platforms. In the absence of face-to-face interaction among members of virtual teams, a variety of communication channels must be integrated into the online learning experience in order to provide students with levels of media richness that minimize the "noise" of missing cues in the exchange ofmessages. Students should be requested to alternate use of different communication platforms available in the virtual classroom for different tasks in the course, so that they not only demonstrate their ability to attain certain goals, but also gain a better understanding of processes and resources along the way. This strategy also takes into account the fact that students are likely to have varying skills across various communication platforms.

- Rethinking expectations, processes, and outcomes. In connection with the previous point, it is crucial for instructors to candidly reflect on the functions that virtual teams serve for the overall purposes of their online courses. Not all subjects and instructional goals benefit equally from incorporating teamwork as part of the course's dynamics. Nevertheless, if requesting teamwork is deemed crucial, instructors should allocate enough time within the course's term, and even before it begins, for social bonding. Faculty must be willing to reward efficient communication, problem solving, decision-making, and crisis management within teams, at least as much as effective outcomes are rewarded. 
- Defining basic rules of the game. In lieu of the well-defined organizational cultures that members of virtual teams find in business settings, the instructor should provide online students with a basic set of principles to guide interaction inside the virtual classroom. Such a set of rules should go beyond offering orientation on typical "housekeeping" matters (e.g., submission of assignments, participation in class discussions, grading policies) to also suggest best practices for team members' interaction, remind them of basic norms of "netiquette," and/or introduce students to some specialized terms related to the subject at hand.

- $\quad$ Seamless, timely intervention. Online instructors should assume the role of coach and facilitator of virtual teamwork, rather than one of patrol officer or controller. In this sense, instructors would assume a position equivalent to that of experts within a community of practice, as they gradually surrender control of the learning process to students. However, instructors must be ready for timely interventions to help groups overcome crises in the early stages of team formation. In virtual classes, the roles of students and instructors are transformed to fit the environment. While many traditional classes have become more student-centered, the removal of some sensory cues further affects student-teacher and studentstudent interactions. The same technologies that break down the barriers of space and time erect new barriers between students and between students and instructors. Instructors become coaches, facilitators, or in a certain sense - team managers as they guide the collaborative work and learning of students. As Meyerson et al. (1996, p. 192) suggest in reference to the establishment of swift trust in distributed teams, "unless one trusts quickly, one may never trust at all." Therefore, instructors should be prepared to promptly pinpoint dysfunctions and facilitate problem-solving for teams facing special communication challenges, in order to prevent these challenges from becoming major disruptions in the life of the team.

- Facilitating connection between communities of practices inside and outside the virtual classroom. Instructors and providers of student services within educational institutions could work together in gathering and facilitating information about trade organizations and other communities of practices with which virtual teams could cultivate relationships. Teams should be encouraged to establish formal or informal ties with other CoPs that are relevant for their raison d'être as a group, as this would not only give them an opportunity to look at a course's contents in connection 
with "real life" scenarios, but also allow students to expand their social and professional networks by participating in other CoPs.

- Creating spaces for maintenance of course-originated CoPs over time. Coordinating offices of online and distance education programs in universities and colleges could offer an innovative service to instructors and students by establishing portals or interactive spaces where communities of practices generated by teamwork in different courses continue to exist after their initial academic term is over. The purpose of such a space would be many-fold. First, it would create conditions for successful CoP experiences to survive beyond the limits of a virtual classroom. Second, it would allow the spontaneous creation of a meta-community of practice comprising the universe of online students who are participating or have participated in course-specific CoPs - a community where newcomers could learn best practices from peers who have become experts by virtue of their accumulated experience in virtual teams and online courses. Finally, the space should prove a valuable source of information for the sponsoring college or university, as it would reflect opinions, concerns, and feedback from students who actively participate in the institutions' distance education initiatives.

In light of the germinal status of the existing literature on the subject, our suggestions to create favorable conditions for the development of trust and communities of practice in virtual classrooms are, for the time being, modest ideas in progress. However, we consider them as a starting point for future research aimed at realizing in the electronic space Lave and Wenger's (1991) comprehensive view of authentic generative social practice.

\section{Endnotes}

1 Classes were composed of students in an Organizational Communication course taught in a small private college. This discussion preceded their reading assignments on the functioning of teams in organizations.

2 The notion of anchored instruction refers to the establishment of relevant connections between instructional contents and "real life" issues (Cogni- 
tion and Technology Group at Vanderbilt, 1993). Cognitive apprenticeship occurs when learners become familiar with experts' thought processes and end up adopting their analytical strategies (Collins, Brown \& Newman, 1989). Social learning defines, in the context of our discussion, the process in which community members learn from their peers, by observing their behavior and progress within the group as a whole (Lave \& Wenger, 1991).

\section{References}

Bandow, D. (2001). Time to create sound teamwork. The Journal for Quality and Participation, 24(2), Start page 41. Retrieved Oct. 16, 2001, from ProQuest database.

Barab, S.A., Squire, K.D., \& Dueber, W. (2000). A co-evolutionary model for supporting the emergence of authenticity. Educational Technology, Research, and Development, 48(2), 37-62.

Birk, A. (2001). Learning to trust. In Falcone, R., Singh, M., \& Tan, Y.H. (Eds.), Trust in Cyber-Societies, (pp. 1-7). Berlin: Springer-Verlag.

Bitter-Rijpkema, M., Martens, R., \& Jochems, W. (2002). Supporting knowledge elicitation for learning in virtual teams. Educational Technology \& Society, 5(2). Retrieved from http://ifets.ieee.org/periodical/vol_2_2002/ rijpkema.hmtl.

Cantu, C. (1997). Virtual teams. CSWT Papers. Retrieved from http:// www.workteams.unt.edu/reports/Cantu.html.

Cognition and Technology Group at Vanderbilt. (1993). Anchored instruction and situated cognition revisited. Educational Technology, 33, 52-70.

Collins, A., Brown, J.S., \& Newman, S.E. (1989). Cognitive apprenticeship: Teaching the crafts of reading, writing, and mathematics. In Resnik, L.B. (Ed.), Knowing, Learning, and Instruction: Essays in Honor of Robert Glaser, (pp. 665-692). Hillsdale, NJ: Erlbaum.

Cramton, C. D. (2001). The virtual knowledge problem and its consequences for dispersed Collaboration. Retrieved from http:// www.webuse.umd.edu/abstracts2001/abstract_2001_cramton.htm. 
Crisp, C.B. \& Jarvenpaa, S.L. (2000). Trust over time in global virtual teams. Unpublished manuscript.

Falcone, R., Singh, M., \& Tan, Y.H. (2001). Bringing together human and artificial agents in cyber-societies: A new field of trust research. In Falcone, R., Singh, M. \& Tan, Y.H. (Eds.), Trust in Cyber-Societies, (pp. 1-7). Berlin: Springer-Verlag.

Gould, D. (1999). Virtual organization. Retrieved on June 28, 2002, from the World Wide Web:http://www.seanet.com/ daveg/vrteams.htm.

Handy, C. (1995). Trust and the virtual organization. Harvard Business Review, 73(3), 40-50.

Harrison, R.T., Dibben, M.R., \& Mason, C.M. (1997). The role of trust in the informal investor's investment decision: An exploratory analysis. Entrepreneurship Theory and Practice, 21(4), 63-81.

Henry, J. E. \& Hartzler, M. (1997). Tool for Virtual Teams: A Team Fitness Companion. New York: McGraw-Hill.

International WHERE+HOW (2002). The International Distance Learning Course Finder. Retrieved from: http://www.dlcoursefinder.com.

The Internet Research and Development Centre. Virtual University Journal. Retrieved October 2, 2002 fromhttp://www.irdc.com/virtual-universitypress/vuj/welcome.htm.

Jarvenpaa, S. L. \& Leidner, D. E. (1998). Communication and trust in global virtual teams. Journal of Compute-Mediated Communication, 3(4). Retrieved from http://www.ascusc.org/jcmc/vol3/issue4/jarvenpaa.htm.

Jarvenpaa, S. L., Knoll, K., \& Leidner, D. E. (1998). Is anybody out there? Antecedents of trust in global virtual teams. Journal of Management Information Systems, 14(4), 29-64.

Katzenbach, J. R. \& Smith, D. K. (2001). The discipline of virtual teams. Leader to Leader, 22. Retrieved from http://www.pfdf.org/leaderbooks/ 121/fall2001/katzenbach.html.

Kezbom, D. (2000). Creating teamwork in virtual teams. American Association of Cost Engineers, 42 (10), 33-36. Retrieved October 16, 2001, from ProQuest database.

Kimble, C., Li, F., \& Barlow, A. (2000). Effective virtual teams through communities of practice. Retrieved from http://www.mansci.strath.ac.uk/ papers.html. 
Lave, J. \& Wenger, E. (1991). Situated learning: Legitimate peripheral participation. New York: Cambridge University Press.

Lewicki, R.J., McAllister, D.J., \& Bies, R.J. (1998). Trust and distrust: New relationships and realities. Academy of Management Review, 23, 438458.

Lipnack, J. \& Stamps, J. (1997). Virtual Teams. Retrieved from http:// www.netage.com/Learning/mini_book/Chapter_1_Summary.html.http:/ /www.netage.com/Learning/mini_book/Chapter_2_Summary.html.http:/ /www.netage.com/Learning/mini_book/Chapter_9_Summary.html.

Lurey, J. S. \& Raisinghani, M. S. (2001). An empirical study of best practices in virtual teams. Information and Management, 38(8), 523-544. Retrieved October 16, 2001, from ProQuest database.

Mayer, R.C., Davis, J.H., \& Schoorman, F.D. (1995). An integrative model of organizational trust. Academy of Management Review, 20(3), 709734.

McKnight, D.H. \& Chervany, N.L. (2001). Trust and distrust definitions: One bite at a time. In Falcone, R., Singh, M. \& Tan, Y.H. (Eds.), Trust in Cyber-Societies, (pp. 27-54). Berlin: Springer-Verlag.

Mehrabian, A. (1971). Silent messages. Belmont, CA: Wadsworth.

Meyerson, D., Weick, K.E., \& Kramer, R.M. (1996). Swift trust and temporary groups. In Kramer, R.M. \& Tyler, T.R. (Eds.), Trust in Organizations: Frontiers of Theory and Research, (pp. 166-195). Thousand Oaks, CA: Sage Publications.

Moore, J. \& Barab, S. (in press). The inquiry learning form: A community of practice approach to online professional development. To appear in Technology Trends, 46.

National Center for Education Statistics. (2002). Contexts of Postsecondary Education. Retrieved from http://nces.ed.gov/programs/coe/2002/section5/indicator38.asp.

Online-Educa. (2002). Online-Educa Berlin: $8^{\text {th }}$ International Conference on Technology Supported Learning \& Training. Retrieved from http:/ /www.online-educa.com.

Shaw, R. B. (1997). Trust in the Balance. San Francisco: Jossey-Bass Publishers. 
Squire, K.D. \& Johnson, C.B. (2000). Supporting distributed communities of practice with interactive television. Educational Technology, Research and Development, 48(1), 23-43.

Tidwell, L. C. \& Walther, J. B. (2000). Getting to know one another a bit at at time: Computer-mediated communication effects on disclosure, impressions, and interpersonal evaluations. Paper presented at the 7 th International Conferences on Language and Social Psychology, Cardiff, Wales.

United Nations Development Program. (2001). Human Development Report 2001. Retrieved from http://hdr.undp.org/reports/global/2001/en/pdf/ front.pdf. 